\title{
A traffic Capacity Research for Five-way Roundabouts with Signal Controls
}

\author{
Yang Huiwen \\ MOE Key Laboratory for Urban Transportation Complex Systems Theory and Technology \\ Beijing Jiaotong University \\ Beijing, China \\ 12121017@bjtu.edu.cn
}

\begin{abstract}
Roundabouts that boast safe and smooth traffic flowing have been extensively utilized. Yet as simple roundabouts are not sufficient to cope with the increasing traffic volume, it is necessary to carry out programs on signalized roundabouts. Due to the fact that existing domestic researches on the capacity of roundabouts are limited to regular four-way models, this paper explores a capacity model of five-way roundabouts with signal control. First of all, the author would optimize the existing signal timing of a certain five-way roundabouts with the signal optimization model. Secondly, the author calculates the capacity of each road entry by dividing the entries into major and minor ones based on their traffic volume and quantity of lanes. Then the capacity of each entry is to be added up to get the total capacity of the roundabouts. Last but not least, the Wujiaochang five-way roundabout of Shanghai is taken as a case study for the test of the capacity model, and the result proves that this model presented in this paper enjoys excellent performance.
\end{abstract}

Key words-five-way roundabouts, capacity model, signal timing

\section{INTRODUCTION}

With the expansion of cities in China and the increasing number of vehicles, the traffic of major thoroughfares is undergoing explosive growth. In particular, the traffic capacity of major roundabouts in some metropolitans is in bad condition, and people, vehicles are often caught in jam. Generally speaking, while a large number of vehicles can enter the intersection, little of them can exit at ease. As a result, simple roundabouts cannot meet the increasing traffic demand, and thus more and more programs have attached their focus to the planning and construction of roundabouts with signal-control. In order to effectively manage the intersections with signal control, the traffic capacity of roundabouts should be accurately calculated. Although China has made some achievements in this field, the research of the traffic capacity of signal-controlled intersections is still at its nascent stage. Since the study has been limited to four-way signal-controlled roundabouts, researches are absent on the traffic capacity of five-way roundabouts [1-3]. Therefore, the author would, first and foremost, establish a traffic capacity model of five-way roundabouts with signal control [4] by drawing strength from the existing theories and methods about four-way roundabouts capacity and giving full play to the characteristics of five-way roundabouts, so as to resolve the current problems. Then the author would calculate the traffic capacity of a real life example to verify relevant theories and models proposed in the paper.

\section{BASIC CONSTRAINTS ON INTERSECTION SIGNAL TIMING}

For the signal control methods of five-way roundabouts, it is of utmost importance to resolve the conflict between traffic flow entering and exiting the circular lane. As a matter of fact, this problem can be solved by phase sequence program which perfectly coordinates the inflow and outflow of the traffic and reduces the queuing demand accepted by the road within a certain cycle. Therefore, such a rule is set that the entries of five-way roundabouts are numbered counterclockwise, as shown in Figure 1-1, and the traffic that flows from Entry $i$ to Exit $j(i \neq j)$ is referred to as Traffic Flow $i j$.

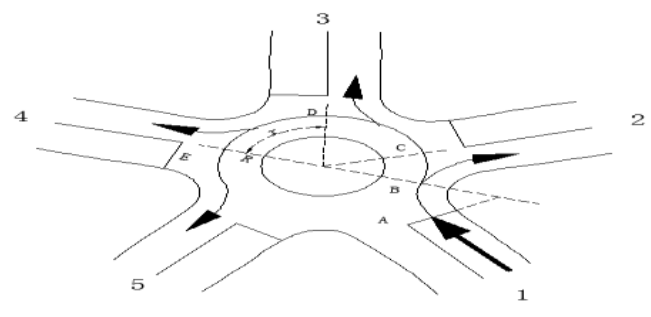

Fig. 1. Diagram of the circulating lane capacity of five-way roundabouts

In addition, as the capacity of the circular lane also holds significance for the signal of five-way intersections, the calculation methods differ based on the different capacities. As shown in Fig.1, the curve ABC represents the path starting from the stop line of the entrance to the stop line of the nearest circular lane in the direction ahead; the curve DE represents the path starting from the stop line of one circular lane to the stop line of its adjacent circular lane[5]. It is the capacities of these two curves that differ from each other. Assuming that the average parking length of a vehicle is $l$, the circulating lane capacity of curve $\mathrm{ABC}$ is $N_{1}$.

$$
N_{1}=\frac{\pi(r \alpha+R \beta) n_{1}}{180 l}
$$

In this equation, $n_{l}$ represents the number of lanes with available queue space in the section of curve ABC .The circulating lane capacity of curve DE is $\mathrm{N}_{2}$.

$$
N_{2}=\frac{\pi R \gamma n_{2}}{180 l}
$$

In this equation, $n_{2}$ represents the number of lanes with available queue space in the section of the curve DE. 


\section{TIMING PARAMETERS OPTIMIZATION MODEL}

The concept of saturation can be utilized to build a model of optimized signal timing for five-way roundabouts. In building the model[6], it is also necessary to consider a bound variable circular lane parking space, so the objective function is as follows:

$$
\min \left(\sum_{i} P_{i}\right)=\min \left(\sum_{i} w_{i}^{d} d_{i}+w_{i}^{s} s_{i}\right)
$$

Constraint conditions:

$$
\left\{\begin{array}{c}
g_{i} \geq g_{i \min } \\
d_{i} \leq d_{i L O S} \\
x_{i} \leq 0.9 \\
n_{i} \leq n_{i \max }
\end{array}\right.
$$

The Eq.3 is five-way roundabouts cycle length performance index function. In this equation, $P_{\mathrm{i}}$ is the natural capacity index of phase $i ; d_{\mathrm{i}}$ is the average delay of phase $i ; s_{\mathrm{i}}$ is the average parking time of phase $i$. In Eq.4, $g_{\mathrm{i}}$ is the effective green light time of phase $i ; d_{\mathrm{i}}$ is the average delay of phase $i ; d_{\mathrm{iLOS}}$ is the maximum delay of phase $i$ if it is to meet the required service level; $x_{\mathrm{i}}$ is the saturation of phase $i ; n_{\mathrm{i}}$ is the length of the vehicles in queue of phase $i ; n_{\text {imax }}$ is circulating lane capacity of phase $i$. The calculation of the signal timing of five-way roundabouts can be optimized with the real-time information in terms of the directions, the volume of the traffic stream, and the time intervals to be optimazed of five-way roundabouts. It is worth noticing that the calculation can only be done when all the above conditions are available.

\section{THE CAPACITY MODEL OF CIRCULATING LANES OF FIVE- WAY ROUNDABOUTS WITH SIGNAL CONTROL}

\section{A. General analysis of the model}

As the entrance lanes differ, sometimes greatly, in their traffic volume, they can be divided into major and minor ones. Signal lights are set to shorten the traffic cycle and reduce delays, a condition which determines whether the traffic volume is large enough for a certain lain to be equipped with signal lights. Therefore, it might be, generally speaking, unnecessary to equip the minor lanes with signal lights, which otherwise might probably lead to more frequent delays. By contrast, the traffic capacity of major lanes might be, to some extent or even significantly, enhanced with the facilitation of signal lights.

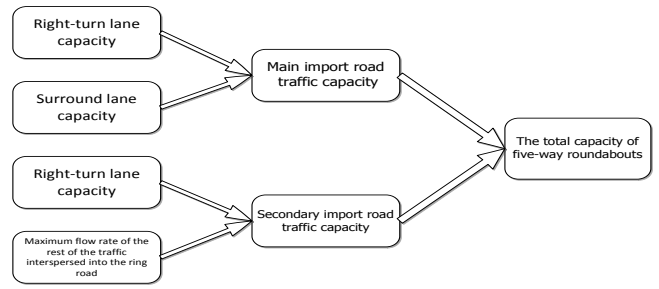

Fig. 2. Traffic capacity model of circulating lanes of five-way roundabouts with signal control
In this paper, the author defines that circular lanes refer to all the entrance lanes but the right-turn ones of the five-way roundabout model with signal control. Therefore, the traffic capacity of a major entrance lane is equal to the traffic capacity of a circular lane multiplied by the total number of the circular lanes, coupled with the traffic capacity of an exclusive rightturn lane. For a minor entrance lane, its traffic capacity is equal to the capacity of a circular lane, which is evaluated with the utilization of the gap-accepted theory, multiplied by the number of the entrance lanes, coupled with the traffic capacity of an exclusive right-turn lane. Then the model of the total traffic capacity of a five-way roundabout with signal control can be shown in Fig. 2.

\section{B. The traffic capacity of exclusive right-turn lanes}

Right-turn vehicles on a roundabout might not be subject to the impact of signal lights [7]. Given this condition, the maximum traffic capacity (vehicles / h) of an exclusive rightturn lane is:

$$
C_{r}=3600 / t_{r}
$$

In this equation, $t_{\mathrm{r}}$ is the average minimum safety headway distance of right-turning vehicles, and $v$ is the speed of the traffic flow. If the proportion $\beta$ r of right-turning vehicles on the entrance lane is known, the formula of the traffic capacity of the exclusive right-turn lane can be as follows (vehicles / h):

$$
C_{r}=C_{\text {entry }} \bullet \beta_{r}
$$

In this equation, $C_{\text {entry }}$ is the capacity of the entrance lance, vehicles / h.

\section{The traffic capacity of circular lanes}

The traffic capacity of a circular lane can be affected by many factors, such as the signal cycle of the roundabout, the intervals of traffic lights and so on. Assuming that an intersection is controlled by signal, $t_{\mathrm{r}}, t_{\mathrm{g}}, t_{\mathrm{y}}$ represent the duration of the red, green and yellow traffic lights respectively, and $\mathrm{T}$ represents the signal cycle. If the situation that a vehicle parks for the second time on the roundabout is excluded, then the traffic capacity of a straight lane is:

$$
N_{s}=\frac{3600 \varphi_{s}\left[\left(t_{g}-t_{\text {first }}\right) / t_{s}+1\right]}{T}
$$

In this equation, $t_{\text {first }}$ represents the time interval when the first car starts to move until it passes the stop line after green light turns on; $t_{\mathrm{s}}$ represents time interval of the minimum headway distance when the vehicles pass the stop line in a row; $\varphi_{\text {s }}$ is correction coefficient. When vehicles on the roundabout are not disturbed by bicycles or pedestrians, $\varphi$ s can be approximately 1.0 .

\section{CASE Study}

Wujiaochang roundabout of Shanghai consists of five roads, namely Songhu Road, Xiangyin Road, Huangxing Road, Siping Road, Handan Road. Figure 1 shows that the roundabout consists of five circular lanes, of which the outermost one is an exclusive right-turn lane. Songhu Road, Handan Road, Huangxing Road and Yinxiang Road are the 
major entrance roads with signal control and they all have green belts between the two-way traffic.

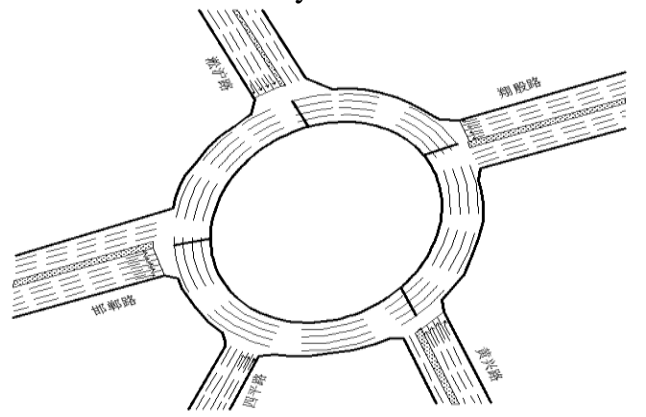

Fig. 3. The schematic plan of Wujiaochang roundabout in Shanghai

However, as Siping Road has less traffic volume, it is an entrance lane without signal control. It is observed that the time interval of the headway distance of the vehicles turning right in a row on Yinxiang Road, Songhu Road, Siping Road, Handan Road and Huangxing Road are 6.28s, 8.61s, 5.77s, 6.92s and $5.60 \mathrm{~s}$ respectively. Thus the average time interval is $6.64 \mathrm{~s}$ [8]. It is also observed that the signal cycle of Wujiaochang roundabout is 108s. The duration of all green signal lights and the phase differences are shown in Table I .

TABLE I. SIGNAL TIMING PARAMETERS OF THE SIGNAL LIGHTS OF APPROACH AND DEPARTURE LANES LEADING TO WUJIAOCHANG ROUNDABOUT

\begin{tabular}{|c|c|c|}
\hline Traffic Flow & $\begin{array}{c}\text { The start time of } \\
\text { green lights(s) }\end{array}$ & $\begin{array}{c}\text { The duration of green } \\
\text { lights(s) }\end{array}$ \\
\hline Approach of Yinxiang Rd & 75 & 30 \\
\hline Approach of Songhu Rd & 17 & 30 \\
\hline Approach of Handan Rd & 64 & 41 \\
\hline Approach of Hangxing Rd & 17 & 30 \\
\hline Exit of Yinxiang Rd & 0 & 72 \\
\hline Exit of Songhu Rd & 50 & 72 \\
\hline Exit of Handan Rd & 0 & 61 \\
\hline Exit of Huangxing Rd & 50 & 72 \\
\hline
\end{tabular}

\section{A. Theoretical calculation results of traffic capacity}

Firstly, the existing signal timing is optimized by the signal optimization model. The optimized signal cycle is 106s. the signal timing of traffic flow in each direction is shown in Table II.

TABLE II. OPTIMIZED SIGNAL TIMING PARAMETERS OF WUJIAOCHANG ROUNDABOUT

\begin{tabular}{|c|c|c|}
\hline Traffic Flow & $\begin{array}{c}\text { The start time of } \\
\text { green lights(s) }\end{array}$ & $\begin{array}{c}\text { The duration of green } \\
\text { lights(s) }\end{array}$ \\
\hline Approach of Yinxiang Rd & 61 & 42 \\
\hline Approach of Songhu Rd & 15 & 20 \\
\hline Approach of Handan Rd & 56 & 25 \\
\hline Approach of Hangxing Rd & 3 & 38 \\
\hline Exit of Yinxiang Rd & 0 & 58 \\
\hline Exit of Songhu Rd & 38 & 80 \\
\hline Exit of Handan Rd & 84 & 75 \\
\hline Exit of Huangxing Rd & 44 & 62 \\
\hline
\end{tabular}

The calculation results of the traffic capacity of each entrance lane and sub-lane are shown in the chart below:
TABLE III. THE THEORETICAL CALCULATION RESULTS OF THE TRAFFIC CAPACITY OF WUJIAOCHANG ROUNDABOUT

\begin{tabular}{|c|c|c|c|c|c|}
\hline Approaches & $\begin{array}{l}\text { Yinxiang } \\
\text { Rd } \\
\end{array}$ & $\begin{array}{l}\text { Songhu } \\
\text { Rd } \\
\end{array}$ & $\begin{array}{l}\text { Handan } \\
\text { Rd } \\
\end{array}$ & $\begin{array}{l}\text { Siping } \\
\text { Rd } \\
\end{array}$ & $\begin{array}{l}\text { Huangxing } \\
\text { Rd } \\
\end{array}$ \\
\hline $\mathrm{Nr}$ & 573 & 418 & 624 & 520 & 643 \\
\hline $\begin{array}{c}\text { The number } \\
\text { of } \\
\text { right-turn } \\
\text { lanes }\end{array}$ & 1 & 1 & 1 & 1 & 1 \\
\hline Ns & 274 & 289 & 277 & - & 287 \\
\hline $\begin{array}{l}\text { The number } \\
\text { of } \\
\text { circular lanes }\end{array}$ & 3 & 2 & 4 & - & 3 \\
\hline $\mathrm{Sc}$ & - & - & - & 315 & - \\
\hline $\begin{array}{c}\text { The number } \\
\text { of } \\
\text { free lanes }\end{array}$ & - & - & - & 3 & - \\
\hline $\begin{array}{c}\text { Total traffic } \\
\text { capacity }\end{array}$ & 1395 & 996 & 3 & 1465 & 1504 \\
\hline
\end{tabular}

Note: The traffic rate of the circular lanes is 1.4 cars per second when the $S_{\mathrm{c}}$ of Siping road is calculated.

From the above chart, it is shown that the theoretical design traffic capacity of Yinxiang Road, Songhu road, Handan Road and Huangxing Road are 1395 pcu/h, 996 pcu/h, $1732 \mathrm{pcu} / \mathrm{h}$ and $1504 \mathrm{pcu} / \mathrm{h}$ respectively. Taking the actual situation into consideration, the actual traffic capacity is $80 \%$ of the design traffic capacity, hence $1116 \mathrm{pcu} / \mathrm{h}, 797 \mathrm{pcu} / \mathrm{h}$, $1386 \mathrm{pcu} / \mathrm{h}$ and $1203 \mathrm{pcu} / \mathrm{h}$ respectively. However, the traffic flow rate of the circular lanes ranges from 1.3 to 1.6 cars per second. The theoretical traffic capacity of Siping road ranges from $1354 \mathrm{pcu} / \mathrm{h}$ to $1683 \mathrm{pcu} / \mathrm{h}$, while the actual traffic capacity ranges from $1083 \mathrm{pcu} / \mathrm{h}$ to $1269 \mathrm{pcu} / \mathrm{h}$. Based on these figures, the average traffic capacity thus stands at $1176 \mathrm{pcu} / \mathrm{h}$.

\section{B. The actual traffic capacity of Wujiaochang roundabout}

According to the obseravtion of Wujiaochang of Shanghai, the traffic volume at pead hour and off-peak hour is show in Table IV and Table V.

TABLE IV. THE VOLUME AND DIRECTIONS OF THE TRAFFIC FLOW OF THE APPROACH LANES AT WUJIAOCHANG ROUNDABOUT AT RUSH HOUR

\begin{tabular}{|c|c|c|c|c|c|c|}
\hline $\begin{array}{c}\text { Traffic } \\
\text { volume } \\
\text { (pcu/h }\end{array}$ & $\begin{array}{c}\text { Exitof } \\
\text { Yinxiang } \\
\text { Rd }\end{array}$ & $\begin{array}{c}\text { Exit of } \\
\text { Songhu } \\
\text { Rd }\end{array}$ & $\begin{array}{c}\text { Exit of } \\
\text { Handan } \\
\text { Rd }\end{array}$ & $\begin{array}{l}\text { Exit } \\
\text { of } \\
\text { Siping } \\
\text { Rd }\end{array}$ & $\begin{array}{l}\text { Exit of } \\
\text { Huang } \\
\text { xing } \\
\text { Rd }\end{array}$ & Total \\
\hline $\begin{array}{c}\text { Approach } \\
\text { of } \\
\text { Yinxiang } \\
\text { Rd }\end{array}$ & 0 & 147 & 223 & 426 & 269 & 1065 \\
\hline $\begin{array}{c}\text { Approach } \\
\text { of Songhu } \\
\text { Rd }\end{array}$ & 143 & 0 & 143 & 264 & 171 & 721 \\
\hline $\begin{array}{c}\text { Approach } \\
\text { of Handan } \\
\text { Rd }\end{array}$ & 336 & 315 & 0 & 596 & 384 & 1631 \\
\hline $\begin{array}{c}\text { Approach } \\
\text { of Siping } \\
\text { Rd }\end{array}$ & 291 & 189 & 189 & 0 & 352 & 1021 \\
\hline $\begin{array}{c}\text { Approach } \\
\text { of } \\
\text { Huangxing } \\
\text { Rd }\end{array}$ & 365 & 234 & 235 & 452 & 0 & 1286 \\
\hline
\end{tabular}


TABLE V. THE VOLUME AND DIRECTIONS OF THE TRAFFIC FLOW OF THE ENTRANCE LANES AT WUJIAOCHANG ROUNDABOUT AT RUSH HOUR

\begin{tabular}{|c|c|c|c|c|c|c|}
\hline $\begin{array}{c}\text { Traffic } \\
\text { volume } \\
(\text { pcu/h }\end{array}$ & $\begin{array}{c}\text { Exitof } \\
\text { Yinxiang } \\
\text { Rd }\end{array}$ & $\begin{array}{c}\text { Exit of } \\
\text { Songhu } \\
\text { Rd }\end{array}$ & $\begin{array}{c}\text { Exit of } \\
\text { Handan } \\
\text { Rd }\end{array}$ & $\begin{array}{l}\begin{array}{l}\text { Exit } \\
\text { of } \\
\text { Siping } \\
\text { Rd }\end{array} \\
\end{array}$ & $\begin{array}{l}\text { Exit of } \\
\text { Huang } \\
\text { xing } \\
\text { Rd }\end{array}$ & Total \\
\hline $\begin{array}{l}\text { Approach } \\
\text { of } \\
\text { Yinxiang } \\
\text { Rd } \\
\end{array}$ & 0 & 116 & 175 & 386 & 216 & 893 \\
\hline $\begin{array}{c}\text { Approach } \\
\text { of Songhu } \\
\text { Rd }\end{array}$ & 109 & 0 & 107 & 211 & 124 & 551 \\
\hline $\begin{array}{c}\text { Approach } \\
\text { of Handan } \\
\text { Rd }\end{array}$ & 270 & 260 & 0 & 565 & 345 & 1440 \\
\hline $\begin{array}{l}\text { Approach } \\
\text { of Siping } \\
\text { Rd }\end{array}$ & 260 & 154 & 159 & 0 & 310 & 883 \\
\hline $\begin{array}{l}\text { Approach } \\
\text { of } \\
\text { Huangxing } \\
\text { Rd }\end{array}$ & 302 & 188 & 175 & 392 & 0 & 1057 \\
\hline
\end{tabular}

The traffic capacity stands at $5724 \mathrm{pcu} / \mathrm{h}$ at peak hour and $4824 \mathrm{pcu} / \mathrm{h}$ at off-peak hour. By contrast, the traffic capacity calculated by the model is 5674 pcu / h. While the traffic capacity calculated by the model is $8 \%$ lower than the actual traffic capacity at peak hour, and The traffic capacity calculated by the model is $17 \%$ (about $250 \mathrm{pcu} / \mathrm{h}$ ) higher than the actual traffic capacity in normal hour. Therefore, it could be concluded that the gap is narrow.

\section{CONCLUSION}

The author builds a traffic capacity model of five-way roundabouts on the basis optimizing signal timing. First of all, the model is analyzed in detail with the help of the GapAcceptance Theory of traffic alternation and the Weave Theory of roundabouts. Secondly, the uncertainty of the traffic capacity calculation is reduced as much as possible with the optimization of signal timing. Additionally, the entrance lanes of a roundabout are divided into major and minor ones according to their traffic volume and the number of entrance lanes. Thirdly, the traffic capacity of each entrance lane is added up, which equals to the total traffic capacity of the roundabout. Last but not least, the author uses Wujiaochang roundabout in Shanghai as a case study to verify the model and proves it to be effective.

\section{REFERENCES}

[1] Yuan Jinjin,Yuan Zhenzhou, “ Comparison Analysis of Calculation Methods for Traffic Capacity at Signal Junction,"in Technology of Highway and Transport,China,vol.23,pp.123128,May,2006.

[2] Ebrahim F M, Zeinab S, Reza S M, " Characteristics of vehicular traffic flow at a roundabout," in Physical Review, China, vol .70,pp. 45-47,April,2004.

[3] Girianna M, Benekohal R F, " Signal coordination for a twoway street network with oversaturated intersections,"in Transportation Research Board 2003 Annual Meeting.

[4] Gao Yunfeng,Yang Xiaoguang,Wang Tao, "The Model for the Coordinated Control on Five-Leg Roundabouts Based on the Constraint of the Circulating Lane Capacity,"in Systems Engineering, China,vol.24,pp.27-31,August,2006.

[5] Wang Wei, "Fork in the road design new ideas - the combination of the roundabout and traffic signal,"in Traffic \& Transportation, China,vol.2,pp.10-11, $2006 .$.

[6] Shi Quan,Wu Zhong, "Research on Traffic Capacity of Round Crossing,"in Communications Standardization, China,vol.6,pp.156-158, 2006.

[7] Liu Huibin,Deng Wei,Li Dongy, "Research on signal control method for complex roundabout,"in Road Traffic \& Safety, China,vol.2,pp.39-43, 2008.

[8] Li Ping, "On Circle Traffic Organization Design of Wujiaochang in Shanghai,"in China Municipal Engineering, China,vol.8,pp.20-21, 2010. 